\title{
PRODUCTION OF BIOETHANOL FROM RICE STRAW USING YEAST EXTRACTS PEPTONE DEXTROSE
}

\author{
D. Y. Tsunatu1, ${ }^{1}$, K. G. Atiku², T. T. Samuel ${ }^{3}$, B. I. Hamidu ${ }^{4}$ and D. I. Dahutu ${ }^{5}$ \\ 1 Department of Agricultural and Bio-Resources Engr., TARABa State University, Jalingo, TARABa StATE, NIGERIA \\ ${ }^{2}$ Chemical Engineering Department, University of Maiduguri, Maiduguri, Borno State, NigERIA \\ 3,4 Department of Chemistry, Taraba State University, P.M.B 1167, Jalingo-Taraba State, NiGERIA \\ 5 Bio-resources Development Centre (BIODEC), Jalingo CEnTre, TARABA State, NIGERIA \\ E-mail addresses.1 tsunatu.danlami@yahoo.co.uk, ${ }^{2}$ kgatiku@yhoo.com, ${ }^{3}$ ticksontee@gmail.com, ${ }^{4}$ ishakuhamidu@ymail.com, \\ 5 didahutu@yahoo.com
}

\begin{abstract}
The production of bio-ethanol from Rice Straw (Oryza sativa) was carried out using rice straw as a feedstock and a combination of Yeast Extracts Peptone Dextrose (YEPD)at 0.2\%(w/v) $0.4 \%(\mathrm{w} / \mathrm{v}), 0.6 \%(\mathrm{w} / \mathrm{v}), 0.8 \%(\mathrm{w} / \mathrm{v})$ and $1 \%(\mathrm{w} / \mathrm{v})$ concentrations and Saccharomyces cerevisiae (yeast) at 0.5\% (w/v), 1\%(w/v), 1.5\%(w/v),2\%(w/v) and 2.5\%(w/v) concentrations as cells for fermentation. The study determined the most suitable pre-treatment method from the following pretreatment methods; $1 \mathrm{M} \mathrm{NaOH}$ and heating. IM NaOH pre-treatment gave the highest cellulose and lowest lignin content. The effects of substrate concentration values of $1 \mathrm{~g} / \mathrm{l}, 2 \mathrm{~g} / \mathrm{l}, 4 \mathrm{~g} / \mathrm{l}, 6 \mathrm{~g} / \mathrm{l}$ and $8 \mathrm{~g} / \mathrm{l}$; with particle size of $300 \mu \mathrm{m}$ and cell loading combination of YEPD at $0.2 \%(\mathrm{w} / \mathrm{v}) 0.4 \%(\mathrm{w} / \mathrm{v}), 0.6 \%(\mathrm{w} / \mathrm{v}), 0.8 \%(\mathrm{w} / \mathrm{v}), 1 \%(\mathrm{w} / \mathrm{v})$ concentrations and Saccharomyces cerevisiae (yeast) at $0.5 \%(w / v), 1 \%(w / v), 1.5 \%(w / v), 2 \%(w / v), 2.5 \%(w / v)$ on the fermentation process were investigated to obtain optimum conditions of fermentation. The optimum conditions of fermentation were obtained at temperature of $33^{\circ} \mathrm{C}, \mathrm{pH}$ value of 4.0 , substrate concentration of $4 \mathrm{~g} / \mathrm{l}$, particle size $300 \mu \mathrm{m}$ and YEPD to yeast ratio of $0.8 / 1.5$ after 72 hours of fermentation time. Also substrate concentration of $4 \mathrm{~g} / \mathrm{l}$, gave highest bioethanol yield of $49.50 \%$.
\end{abstract}

Keywords: Bioethanol, Oryza sativa, Saccharomyces cerevisiae, Fermentation, Yield, Substrate.

\section{INTRODUCTION}

Bioethanol from renewable resources has been of interest in recent decades as an alternative fuel to the present fossil fuels. Lignocelluloses biomass like wood and agricultural crops residue, e.g. elephant grass, rice straw and sugarcane beet pulps are important raw materials for producing many important value products like fuel ethanol and biodiesel. Up to $75 \%$ of the lignocelluloses are polysaccharides [3]. These renewable raw materials look promising for changing environmentally non friendly fossil hydrocarbon raw materials and hence forming "green" products. In contrast to traditional fuels fermentation bioethanol does not contribute to the greenhouse effect, being a coz neutral resource. Rice straw is by-product of rice production and great bio resources it is one of the abundant lignocellulosic waste materials in the world. It annually produced about 731 million tons, which is shared in Africa 20.9 million tons, Asia 667.6 million tons and Europe 3.9 million. Rice straw can produced 205 billion liters of bioethanol per year which is about $5 \%$ of total consumption. It is the biggest amount from a single biomass feedstock. Rice straws predominately have cellulose $32-47 \%$ hemicelluloses $19-27 \%$ and lignin 5$24 \%$, ashes $18.8 \%$. The pentose's are stronger in hemicelluloses which xylose is the most vital sugar followed by arabinose and hexoses. The carbohydrates of rice straw involve glucose $40-43 \%$ xylose $14.8-19.3 \%$ arabinose $2.7-4.5 \%$ mannose $1.8 \%$ and galactose $0.4 \%$ $[11,13]$. Increasing gas prices and environmental concerns in recent years have now become the pushing force for expanding alternative energy sources. Bioethanol is a pure-burning renewable materials that be produced from ferment cellulosic biomass, bioethanol does not add to a net $\mathrm{CO}_{2}$ atmospheric increase, thus there is no support to global warning burning of bioethanol result in relatively low taking of escape organic compounds carbon monoxide and nitrogen oxide. The advantage of the biomass based bioethanol production has undergone a huge expansion in the years back [10]. However, further cost of the traditionally used (sugar containing) raw materials represent the main part

* Corresponding author, tel: +234- 703 - 960- 0206 
of the total production cost constitutes about 39.9\%$70 \%$ of production cost using less important materials, like agricultural waste, can reduce the expense significantly. Lignocellulosic materials act as promising option to a feedstock for bioethanol production considering their input/output energy ratio, their great availability both in tropical and temperate nation, their low cost (primarily related to their transport) and their bioethanol yields. One of the importances of the use of lignocellulosic biomass is that this feedstock is not directly related to food production. This mean that the production of bioethanol without the need of putting much extension of fertile cultivable land for cropping. Rice exclusively dedicated to the life energy production. More to that, lignocellulosic is a materials that can process in diverse ways for production of many other product like synthesis gas, methanol, hydrogen electricity. Taraba State is the highest rice producer in the near north region, where rice cultivation area occupies over 1.020,000 in the upper Benue of Bantaje, Taraba state Fadden with an average farm yield of 3.75 tons/Fadden and an approximate straw production of 1.4 tons/ Fadden now the main post-harvest rice residues is field open air burning. Although field burning provides effective destruction of weed seeds and pathogenic microbial spores. The produced black smoke represents a threat to the public health. In Taraba state, rice cultivation and wood industries results in the accumulation of large quantities of agricultural waste rich in cellulose. hemicelluloses and lignin which are ready with free cost throughout the year not only in farms but also in private homes once these technological limitation are overcome lignocellulosic biomass will be the main feedstock for bioethanol production. Certainly, a detailed economic and environmental evaluation of different feedstock is required in order to make decision on the most appropriate raw materials for fuel bioethanol production in each case. An important approach for performing such evaluation is to employ simulation tools based on realistic data form from existing bio-ethanol production facilities, pilot plants or mathematical models. Example of these comparative studies have been done for rice straw and lignocellulosic ethanol for rice straw bioethanol and for lignocellulosic biomass cellulose and hemi-cellulose which are the principal bio degradable protein component of the bagasse are found together with lignin in an intense cross linked, rigid lignocelluloses complex, this lignocellulosic structure severely limits the biological hydrolysis of cellulose and other polymers.

The objective of this work was to develop an effective method for pretreatment and enzymatic saccharification of cellulose and hemicelluloses components of rice straw by YEPD into fermentable sugars, as well as fermentation of the hydrolyzate to bioethanol by Saccharomyces cerevisiae strains.

\section{MATERIALS AND METHODS}

\subsection{Sample Collection/Preparation}

The rice straw was obtained from Tsunatu farm along River Nukkai, Jalingo (T.F.R.N.J). It was dried to a constant weight in an oven at a temperature of $110^{\circ} \mathrm{C}$ for 24 hours, it was then size reduce using manual miller and a screen analysis was carried out with various sizes to obtain desired particle sizes.

\subsection{Pre-Treatment of Substrate}

Pretreatment such as alkaline pretreatment and boiling were carried out to determine the quality of pretreatment method; $30 \mathrm{~g}$ of substrates was added to $200 \mathrm{ml}$ of solution (distilled water), after pretreatment the samples were filtered and washed repeatedly with distilled water until a $\mathrm{pH}$ of 7 was obtained. The rice straw was then dried in an oven at $50^{\circ} \mathrm{C}$ to a constant dry weight for 24 hours.

\subsection{Saccharification and Fermentation (SF) of Rice Straw}

The conversion of cellulose biomass to useful substances such as liquid fuels through the enzymatic hydrolysis of polysaccharide, into fermentable sugar, still suffers severe problems that are economical and technical in nature. The economic problems consist exclusive of cost of production and purification of hydrolytic enzymes. It has been suggested therefore that any means that is capable of reducing this cost significantly would have a dramatic effect on the cost of production of useful substance, such as ethanol from renewable resources [14]. The process was found to increase yield of ethanol not only by eliminating inhibition effects, but also by eliminating the need for separate reactors for saccharification and fermentation [1].

In typical run, $200 \mathrm{ml}$ of $0.1 \mathrm{M}$ sodium hydroxide solution was poured into $250 \mathrm{ml}$ conical flask, $0.5 \mathrm{~g}$ YEPD, $2 \mathrm{~g}$ of treated rice straw were introduced. The flask was corked properly, sealed with aluminum foil paper and kept at temperature of $30^{\circ} \mathrm{C}$ for 2 days in an incubator. All the experiment was performed in triplicate. Samples were withdrawn every day for analysis.

\subsection{Pre-Treatment with Alkali}

The important of pre-treatment of lignocellulosic materials has been observed for a long time [5]. The mission of pre-treatment process is to take away lignin and hemicellulose, reduce crystallinity of cellulose, and expand the porosity of the lignocellulosic material. The powdered Rice Straw was separately treated with alkali solution to swell the cellulose and make it available for enzyme hydrolysis. The method described by [17] was employed. Powdered sample (50 g) was measured into a 
$500 \mathrm{ml}$ Erlenmeyer flask containing $250 \mathrm{ml}$ of sodium hydroxide solution $(0.25 \mathrm{~N})$ and brought to boil on a Bunsen flame. The sample was left in suspension for 24 hours after which it was washed several times with distilled water. The $\mathrm{pH}$ of the water was monitored until pH 7.0 was attained. The residue was drained through muslin cloth, air dried for 6 hours and dried again in electric oven at $65^{\circ} \mathrm{C}$ to constant weight. The dried powder was then stored in sealed polythene bags at room temperature [16].

\subsection{Organism Used for Fermentation}

Baker's yeast, Saccharomyces cerevisiae used for fermentation was cultured on yeast extract agar. Dried yeast sample $(1 \mathrm{~g})$ was added to $10 \mathrm{ml}$ of sterile distilled water in MacCartney bottle. The bottle was shaken rigorously for even distribution of the cells. An aliquot $(0.1 \mathrm{ml})$ of the cell suspension was then used to inoculate Yeast Peptone Dextrose Agar (YPDA) medium. Plates were incubated at $28 \pm 2^{\circ} \mathrm{C}$ for $48 \mathrm{hrs}$. Colonies were purified by sub culturing on YPDA and pure culture was maintained on agar slants at $4^{\circ} \mathrm{C}[18]$.

\subsection{Yeast Peptone Dextrose Agar (YPDA)}

Yeast Peptone Dextrose Agar comprised of $\left(\mathrm{gl}^{-1}\right)$ yeast extracts, 10.0; peptone, 10.0; glucose, 20.0; and agar, 20.0. The components were measured into 1 litre distilled water in Erlenmeyer flask, dissolved and sterilized in an autoclave at $121^{\circ} \mathrm{C}, 15 \mathrm{psi}$ for 15 minutes. After sterilization, the agar medium was distributed into sterile Petri dishes and used immediately.

\subsection{Distillation Set-Up at T.S.U Chemistry Research Laboratory, Jalingo}

This was carried out at TSU laboratory using distillation apparatus (Set-Up), Figure 1. The fermented rice straw broth was decanted and transferred into round bottom flask and placed on a heating mantle fixed to a distillation column fitted with a thermometer enclosed in running tap water. Anti-bumping chips were also added in to flask for even distribution of heat. Another flask was fixed to the other end of distillation column to collect the distillate at temperature between $\left(70-90^{\circ} \mathrm{C}\right)$, the volume of bioethanol distillation was measured and recorded. This was done for each of the fermented broth.

\section{BIOETHANOL ANALYSIS}

\subsection{Determination of Quantity of Bioethanol Produced}

The distillate collected was measured using measuring cylinder and expressed as quantity of bio-ethanol produce $\mathrm{g} / \mathrm{l}$ was calculated using:

$$
Y=\frac{V_{E}}{V_{M}} \times 100 \%
$$

In (1), $Y$ is the yield of bioethanol, $V_{E}$ and $V_{M}$ is the volume of bioethanol distillate and fermented mixture distilled respectively.

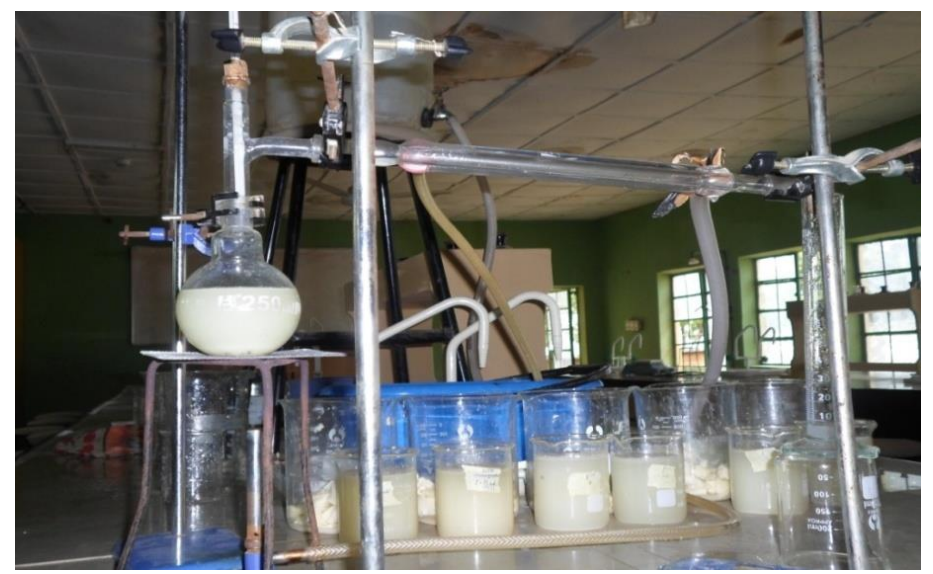

Figure 1: Distillation Set-Up for the production of Bio-ethanol from Rice Straw

\subsection{Titratable Acidity Test}

Titratable acidity (i.e. level of acidity) was obtained by titration with $\mathrm{NaOH}$ solution using phenolphltalain as indicator [2]. This was achieved by using a total volume of $4 \mathrm{M} / \mathrm{NaoH}$ used to neutralize the existing acid.

\subsection{Test for Sulphate}

Sulphate test was gotten by using $1 \mathrm{ml}$ of barium chloride solution was added drop wise (up to $0.5 \mathrm{ml}$ ) to $1 \mathrm{ml}$ bioethanol for the possible formation of barium sulphate, a salt insoluble in water solution and the result signified no present of sulphate.

\subsection{Test for Chloride Ions}

The presence of chloride ion was studied by drop wise addition up to $1 \mathrm{ml}$ of silver nitrate solution to a $1 \mathrm{ml}$ bioethanol sample for a possible formation of a precipitate of solid silver chloride.

\subsection{Bio-ethanol Clarity}

This was analyzed by transferring sample of bio-ethanol produced to a cuvette and measuring transmittance of light at $650 \mathrm{~nm}$ in a uv-visible spectrophotometer, using double distilled deionizer water and $95 \%$ ethanol as standard.

\subsection{Test for Reducing Sugar (RS)}

Add approximate $4 \mathrm{ml}$ of fermented broth produce into test tubes add $1 \mathrm{ml}$ of Benedict's solution to the sample by swirling for homogeneity. Place the test tube containing the mixture into boiling water both. Wait for some several minutes or until the colour change is complete. Compare the colour of the solution to the reference colour sheet or kit. The relative concentration of the reducing sugar was recorded. 


\subsection{Test for Cyanide (CN-)}

Fill the cuvette approximately $3 / 4$ using the bioethanol produced. Add about $2 \mathrm{ml}$ of picric acid to $4 \mathrm{ml}$ of the bioethanol. Measure the concentration of the cyanide $\left(\mathrm{CN}^{-}\right)$ion using a UV-visible spectrophometer at a wave length of 520nm [15].

\subsection{Effect of Substrate Concentration}

This was done by carrying out the simultaneous saccharification and fermentation at $10 \mathrm{~g} / \mathrm{L}, 20 \mathrm{~g} / \mathrm{L} 30 \mathrm{~g} / \mathrm{L}$, $40 \mathrm{~g} / \mathrm{L}$ and $50 \mathrm{~g} / \mathrm{L}$ substrate concentration, while other reaction parameters were kept constant[4].

\subsection{Effect of Catalyst Concentration}

The effect of catalyst concentration(Baker's yeast) was done by fermenting the rice straw for a period of 2 days at varying catalysts concentration of $0.5,1.0,1.5,2.0,2.5 \mathrm{~g}$ per $200 \mathrm{~g}$ of the size reduced rice straw and $250 \mathrm{ml}$ distilled water added.

\subsection{Effect of $\mathrm{pH}$}

This was investigated by carrying out the fermentation at initial $\mathrm{pH}$ adjusted and to evaluate the effect of $\mathrm{pH}$ on bioethanol yield, the $\mathrm{pH}$ of each hydrolysate was varied ranging from $3,4,5,6$, to 7 . During fermentation the $\mathrm{pH}$ of each setup was monitored at intervals of 1 hour for better stabilization. At the expiration of the fermentation duration bioethanol and reduce sugar were respectively determined and the $\mathrm{pH}$ gave the highest yield of bioethanol was chosen for further experiment.
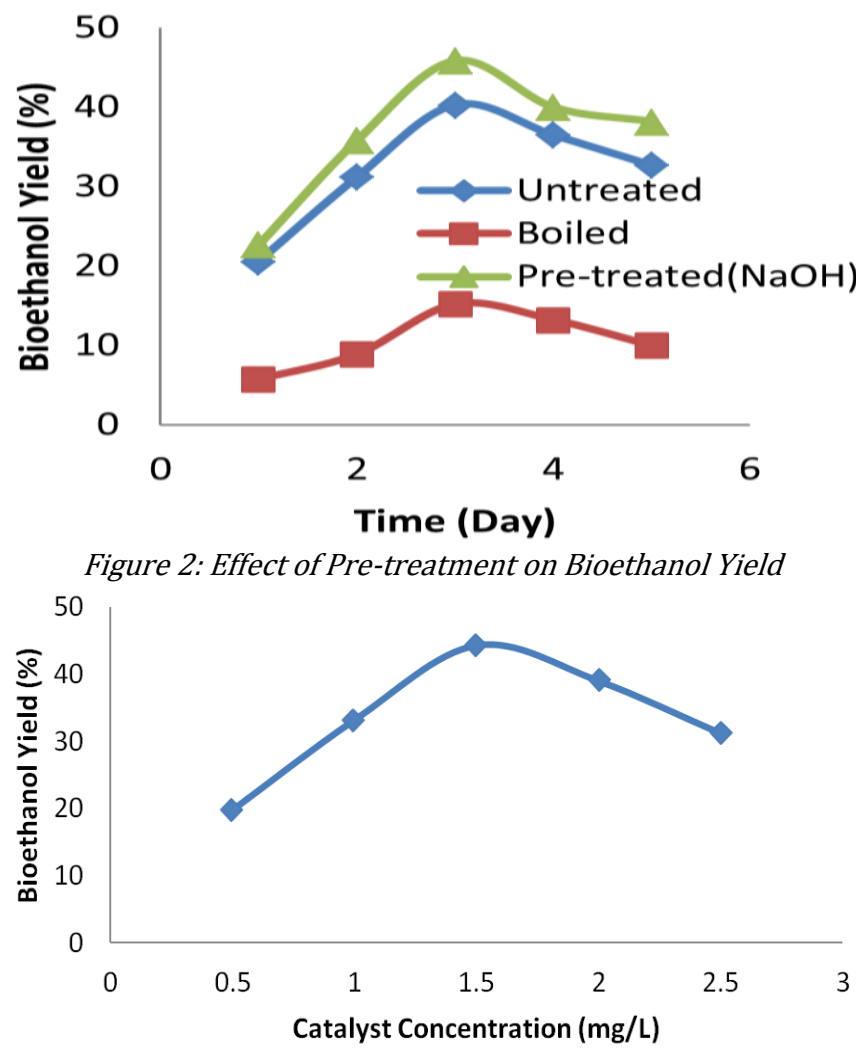

Figure 4: Effect of Catalyst Concentration on Bioethanol Yield

\subsection{Effect of Fermentation Duration}

This experiment was done to determine the residence time and the catalyst concentration that gave the optimum bioethanol yield was chosen as the concentration to be used for varying the fermentation duration of 2,3,4,5,7 days bioethanol and reducing sugar concentration were determined. The time of which maximum bioethanol yield was collected was noted.

\section{RESULTS AND DISCUSSION}

\subsection{Chemical Composition of the Rice Straw}

The analysis of rice straw used in this study showed that it contained $38.24 \%$ cellulose, $29.08 \%$ hemicellulose, $10.63 \%$ lignin and $22.05 \%$ ash and other components as shown in Table 1 . The carbohydrate content of rice straw typically involves glucose (41-43.4\%), xylose (14.8$20.2 \%)$, arabinose (2.7-4.5\%), mannose (1.8\%) and galactose (0.4\%) [9]. Jeya et al., [7] mentioned that the main composition of rice straw was $12 \%$ moisture, $36.8 \%$ cellulose, $25.8 \%$ hemicellulose, $15.8 \%$ lignin while Hashem et al., [3] stated that the main composition of rice straw was $40.84 \%$ cellulose, $28.06 \%$ hemicellulose, $7.86 \%$ lignin and $23.24 \%$ ash and others.

\subsection{Bioethanol Evaluation}

Table 2 provides the basic information obtained from the evaluation of bioethanol.

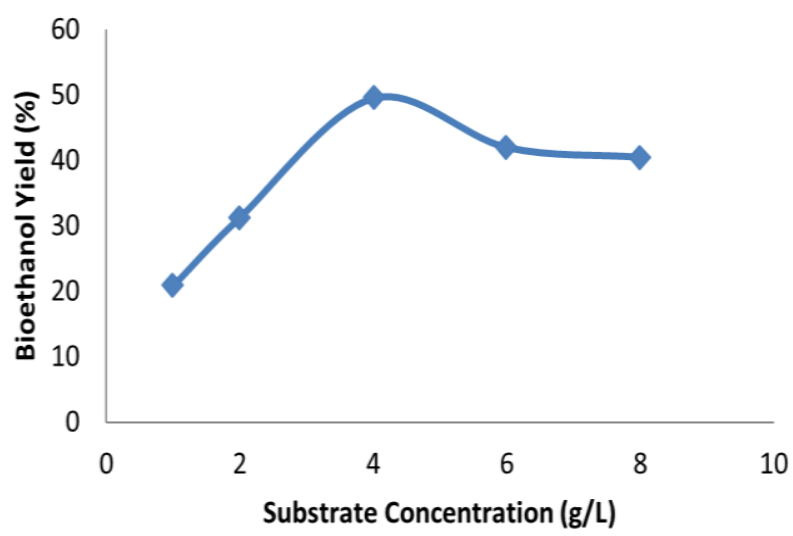

Figure 3: Effect of Substrate Concentration on Bioethanol Yield

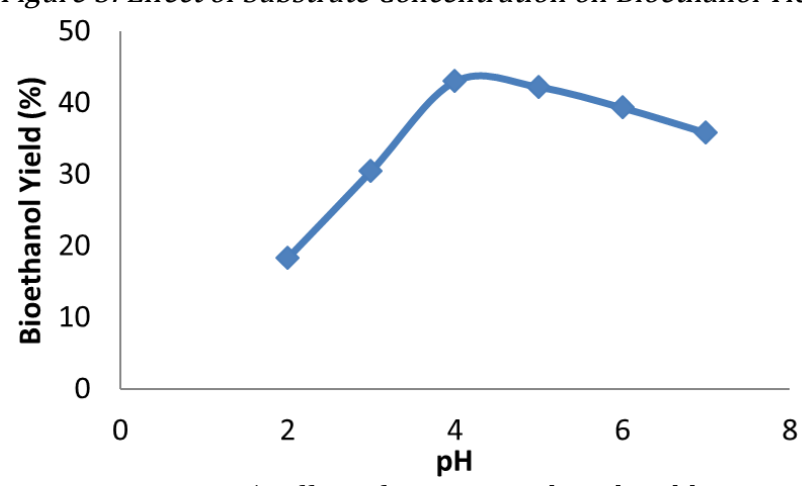

Figure 5: Effect of pH on Bioethanol Yield 
Table 1: Chemical Composition of the Rice Straw Used

\begin{tabular}{lcc}
\hline Constituent & $\begin{array}{c}\text { Percentage of Dry } \\
\text { Weight }\end{array}$ & $\begin{array}{c}\text { Standard } \\
\text { Deviation }\end{array}$ \\
\hline Cellulose & 38.24 & \pm 1.92 \\
Hemicellulose & 29.08 & \pm 1.03 \\
Lignin & 10.63 & \pm 0.73 \\
Ash and Others & 22.05 & \pm 0.51 \\
\hline
\end{tabular}

\begin{tabular}{ll}
\multicolumn{2}{c}{ Table 2: Bio-ethanol physiochemical Analysis } \\
\hline Parameter & Value \\
\hline Bioethanol Yield (\%) & 40.5 \\
pH & 4 \\
TA(ml) & 5 \\
Clarity $(\%)$ & 16.3 \\
Total RS (mg/dL) & 58 \\
Chloride & + \\
Sulphate & - \\
Cyanide (mg/L) & 0.172 \\
\hline
\end{tabular}

Note: $(+)=$ present,$(-)=$ absent. $\mathrm{RS}=$ Reducing Sugars

The result of the physiochemical analysis of bioethanol prepared from rice straw is presented in Table 2. Bioethanol yield, $\mathrm{pH}$, Titratable acidity (T.A), clarity, total reducing sugars, cyanide were all tested on the bioethanol produced. With values presented as $40.50 \%$, $4,5.0,16.3 \%, 58 \mathrm{mg} / \mathrm{dL}$ respectively, chloride was detected and sulphate was not detected.

The result obtained on the effect of fermentation duration on the rate of bioethanol yield when Saccharomyces cerevisiae was exposed to each hydrolysate showed that bioethanol yield reduced progressively with increase in fermentation duration.

\subsection{Effect of Pre-treatment on Bioethanol Yield}

The experiment was done at temperature of $33^{\circ} \mathrm{C}, \mathrm{pH}$ of 4.0 , substrate concentration of $40 \mathrm{~g} / \mathrm{L}, \mathrm{YEPD} /$ yeast ratio $0.8 / 1.5 \%(\mathrm{w} / \mathrm{v})$, and particle size $300 \mu \mathrm{m}$. Figure 2 shows the effect of pretreatment on bioethanol yield. It can be seen from the figure that at (3 days) 72 hours of fermentation time, $40.3 \%$ and $45.85 \%$ yield were attained when untreated and $\mathrm{NaOH}$ pretreated rice straw were fermented respectively. This could be as a result of the presence of soluble sugar in the untreated sample, which was lost during pre-treatment.

\subsection{Effect of Substrate Concentration on Bioethanol Yield}

The effect of substrate concentration on bioethanol yield was studied using rice straw as substrate, the experiment was carried out at different initial substrate concentrate of $1 \mathrm{~g} / \mathrm{L}, 2 \mathrm{~g} / \mathrm{L}, 4 \mathrm{~g} / \mathrm{L}, 6 \mathrm{~g} / \mathrm{L}$ and $8 \mathrm{~g} / \mathrm{L}$. Other reaction conditions kept constant are temperature $33^{\circ} \mathrm{C}, \mathrm{pH}=4.0$, YEPD/yeast ratio $0.8 / 1.5 \%(\mathrm{w} / \mathrm{v})$, and particle size $300 \mu \mathrm{m}$. The result is shown in Figure 3. The result showed that as substrate concentration increases from $1 \mathrm{~g} / \mathrm{L}$ to $4 \mathrm{~g} / \mathrm{L}$, bioethanol yield increased to a maximum of $49.5 \%$ after 72 hours of fermentation. Further increase in substrate concentration up to $8 \mathrm{~g} / \mathrm{L}$ resulted in low bioethanol yield. The decrease in bioethanol yield beyond the optimum concentration of $4 \mathrm{~g} / \mathrm{l}$ could be that at substrate concentration higher than the optimum, there is product inhibition. This implies that the bioethanol produced inhibits the activity of the yeast, hence the drop in bioethanol yield.

\subsection{Effect of Catalyst Concentration on Bioethanol Yield}

$Y E P D$ at fixed concentration keeping other fermentation conditions constant was used. The effect of catalyst concentration on bioethanol yield was investigated. The result is shown in Figure 4, which showed that as catalyst concentration increases from $0.5 \% \mathrm{w} / \mathrm{v}$ to $1.5 \% \mathrm{w} / \mathrm{v}$ bioethanol yield increase from $19.87 \%$ to $44.35 \%$ after 72 hours of fermentation. Further increase in catalyst concentration beyond $1.5 \% \mathrm{w} / \mathrm{v}$ resulted in decrease of bioethanol yield. This may be as a result of more catalyst consuming the limited glucose for self sustenance, thereby resulting in low yield of bioethanol.

\subsection{Effect of $\mathrm{pH}$ on Bioethanol Yield}

The effect of $\mathrm{pH}$ on bioethanol yield was investigated by conducting the fermentation at different controlled $\mathrm{pH}$ of 2.0, 3.0, 4.0, 5.0, 6.0, and 7.0. All other fermentation conditions kept constant were temperature $33^{\circ} \mathrm{C}, 4 \% \mathrm{w} / \mathrm{v}$ substrate concentration, $300 \mu \mathrm{m}$ particle size and YEPD/yeast ratio $0.8 / 1.5 \% \mathrm{w} / \mathrm{v}$. The result is shown in Figure 5. As the pH increased from 2.0 to 4.0 , the bioethanol yield increased to a maximum of $43.6 \%$ at $\mathrm{pH}$ of 4.0. Further increase in $\mathrm{pH}$ to 7.0 resulted in decrease in the yield of bioethanol. The decrease in bioethanol yield may be due to the fact that enzymes are more active in mildly acidic medium ( $\mathrm{pH}$ of 4.0-5.0 for YEPD cells and $\mathrm{pH}$ of 5.0-6.0 for yeast cells), hence the increase in $\mathrm{pH}$ of the medium away from the more acidic medium result in increase in the yield of bioethanol from pH of 2.0 to 4.0. But there was decrease in the yield of bioethanol as the $\mathrm{pH}$ tends towards neutral medium. The reported $\mathrm{pH}$ tolerance range for yeast is 3.5-6.5 while that of $Y E P D$ is 3.5-8.0 [12].

The results prove the ability of Saccharomyces cerevisiae to utilize and ferment the hydrolyzate of alkali pretreated and enzymatic ydrolyzed rice straw. Thus, we could assume the ability of this yeast strain to utilize all types of sugars produced from hydrolysis. However, $S$. cerevisiae utilized only hexoses (glucose).Therefore; the other substitute for bioethanol production can be the formation of xylitol from lignocellulosic hydrolyzates by yeasts such as Candida tropicalisand Candidaguilliermondii [6]. 


\section{CONCLUSION}

From the results obtained from this research the following conclusions were drawn; the best pretreatment condition for rice straw was using $1 \mathrm{M} \mathrm{NaOH}$ for $24 \mathrm{hrs}$ contact time, at $33^{\circ} \mathrm{C}$ and $1: 10$ solid/Liquid ratio. However because of presence of soluble sugar in the untreated sample which is lost during pretreatment, the untreated sample was used in the fermentation. The optimum fermentation conditions obtained were temperature $33^{\circ} \mathrm{C}$, substrate concentration $4 \mathrm{~g} / \mathrm{L}$, particle size $300 \mu \mathrm{m}, \mathrm{pH} 4.0, \mathrm{YEPD} /$ yeast ratio $0.8 / 1.5 \% \mathrm{w} / \mathrm{v}$ and fermentation time of 72 hours (3 days). At optimum substrate concentration of $4 \mathrm{~g} / \mathrm{L}$, bioethanol yield of $49.5 \%$ was obtained.

It should be noted, that the ethanol concentration achieved in this study was not higher than $15 \mathrm{~g} \mathrm{~L}^{-1}$ as a consequence of low rice straw loading. Therefore, in order to achieve higher concentration of ethanol attractive for industrial application, higher rice straw loading is necessary.

\section{CONFLICT OF INTEREST}

Authors declare that they have no conflict of interest.

\section{REFERENCES}

[1] Desphande, V. M., Roman, H. S., and Rao, M. Simultaneous saccharificationand fermentation of cellulose to ethanol using penicillumfumicatosum cellulose and immobilized saccharomyces cerevisiae cells. Biotechnology Bioengineering, 25: 1679-1684. 1983.

[2] Fabro, M. A., Milonesio, H. V., Robert, L. M., Speranza, J. H., Murphy, M., Rodriguez, G. and Castaffed, R. Determination of acidity in all raw milk. Journal of Dairy Science.Vol. (59). pp. 859-861. 2006.

[3] Hashem, M., Ali, E. H. and Abdel-Basset, R. Recycling Rice Straw into Biofuel "Ethanol" by Saccharomyces cerevisiae and Pichia guilliermondii. Journal of Agricultural Science Technology (2013) Vol. (15), pp. 709-7212013.

[4] Highina, B. K., Aderemi, B. O. and Abu, E. The kinetics of glucose production from rice straw by Aspergillus niger .African journal of Biotechnology, 7(11): 17451752. 2006.

[5] Himmel, M. E., Baker, J. O., Overend, R. P. . Pretreatment of lignocellulosic biomass in enzymatic Conversion of Biomass for Fuels Production. Eds.; American Chemical Society: Washington, DC, pp 292324. 1994.

[6] Horitsu, H., Yahahsi, Y., Takamizawa, K., Kawai, K., Suzuki, T. and Watanabe, N. Production of Xylitol from D-xylose by Candida tropicalis: Optimization of Production Rate. Biotechnology and Bioengineering, 40:1085-1091. 1992.
[7] Jeya, M., Zhang, Y. -W., Kim, I. -W. and Lee, J. -K. Enhanced Saccharification of Alkali-treated rice Straw by Cellulase from Trameteshirsutaand Statistical Optimization of Hydrolysis Conditions by RSM. Bioresource Technology, 100: 5155-5161. 2009.

[8] Kaparaju, P., M. Serrano, A.B. Thansen, P. Kongian and I. Angelidai, Bioethanol, biohydrogen and biogas production from wheat straw in a biorefinery concept. Bioresour. Technol., 100: 2562-2568. DOI: 10.1016/j.biortech.2008.11.011 2009,

[9] Karimi, K., Kheradmandinia, S. and Taherzadeh, M. J. Conversion of Rice Straw to Sugars by Dilute-acid Hydrolysis. Biom. Bioen., 30: 247-253. 2006.

[10] Krishna, S. H., Janardhan, R. T. and Chowdary, G. V. Simultaneous saccharification and fermentation of lignocellulosic waste to ethanol using a thermotolerant yeast. Bioresource Technology, 77:193-196. 2001.

[11] Maiorella, B. L. Ethanol. In: Comprehensive Biotechnology, Young, M. (Ed.). Pergamon Press, Oxford, pp: 861-914. 1985.

[12] Rezael, P. S., Najafpour,G.O., Shafaghati, H., and Mahjoub, S. Production of $\alpha$ - Amylase from starch using Aspergillus niger. World applied sciences journal, 7: 306-311. 2009.

[13] Roberto, I. C., S. I. Mussatto and R.C.L.B. Rodrigues, . Dilute-acid hydrolysis for optimization of xylose recovery from rice straw in a semi-pilot reactor. Ind. Crops Prod., 7: 171-176. DOI: 10.1016/S0926-6690(02)00095-X, 2003.

[14] Taniguchi, M., Tanaka, M., Matsuno, R., Kamikulo, T. Evaluation of chemical pretreatment for enzymatic solubilization of rice straw. Biotechnology Bioengineering, 17:110-117. 1983.

[15] Tsunatu D. Y., Taura U. H and Jirah E. U. Kinetic Studies of Bio-sorption of Cyanide Ions from Aqueous Solution using Carbon Black Developed from Shea Butter Seed Husk as an Adsorbent. American Chemical Science Journal. Vol.8 (2) .pp: 111. 2015.

[16] Vlasenko, E. Y., Ding, H., Labavitch, J. M. and shoemaker, S. P. Enzymatic hydrolysis of pretreated rice staw. Bioresource Technology, 59: 109-119. 1997.

[17] Vyas, A., Vyas, D. and Vyas, K. M. Production and Optimization of Cellulases on Pretreated Groundnut Shell by Aspergillus terreus, AV49. J. Scientific Indust Res, 64: 281-6. 2005.

[18] Zakpaa, H. D., Mak-Mensah, E. E. and Johnson, F. S. Production of Bio-ethanol from Corncobs using Aspergillus niger and Saccharomyces cerevisae in Simultaneous Saccharification and Fermentation. Afri. J. Biotechnol. 8 (13): 3018-3022. 2009. 